\title{
Desafios ativistas à democracia deliberativa
}

Activist challenges to deliberative democracy

Já foram cantados em prosa e verso os movimentos por justiça social que protestaram nas ruas, convencidos de que as instituições existentes e os procedimentos normais só reforçavam o status quo. Muitos direitos foram conquistados nas sociedades democráticas, por meio de corajoso ativismo - a jornada de oito horas, o voto feminino, o direito de se sentar em qualquer restaurante. No entanto, a teoria democrática contemporânea raramente reflete sobre o papel da manifestação e da ação direta. ${ }^{1} \mathrm{Na}$ verdade, pode-se imaginar que uma das principais linhagens da teoria democrática contemporânea, a teoria da democracia deliberativa, seja crítica em relação a táticas características do ativismo, como passeatas, boicotes ou ocupações,

\footnotetext{
Iris Marion Young (1949-2006) foi professora de ciência política da Universidade de Chicago, autora, entre outros livros, de Justice and the politics of difference (1990), Inclusion and democracy (2000) e Responsibility for justice (2011).

Este artigo foi publicado originalmente na Political Theory, v. 29, n. 5, outubro de 2001, sob o título "Activist challenges to deliberative democracy". Direitos autorais concedidos pela SAGE Publications. Tradução de Roberto Cataldo Costa. Revisão da tradução por Flávia Biroli. Nota da autora: Agradeço a David Alexander, Mick Burbules, Natasha Levinson, Emily Robertson e Stephen White, bem como a um revisor anônimo da Political Theory, pelos comentários úteis sobre uma versão anterior deste ensaio. Há algumas exceções. Jean Cohen e Andrew Arato (1992) teorizam o lugar dos movimentos sociais e da desobediência civil no contexto da sociedade civil; Os argumentos de John Dryzek sobre a importância dos movimentos de oposição da sociedade civil que estão situados fora do Estado também se referem à atividade de manifestação e protesto. Ver Dryzek (2000), principalmente cap. 4; ver também Dryzek (1996). Não obstante, a distinção entre as normas da deliberação e as normas do ativismo que este ensaio explora não deve ser associada a uma distinção entre Estado e sociedade civil. A sociedade civil é certamente um espaço para a política deliberativa, como muitos já apontaram, inclusive Dryzek, embora também costume ser um espaço para ativismo.
} 
dado que essas são atividades de enfrentamento, em vez de debate, com as pessoas das quais os integrantes do movimento discordam.

Este ensaio constrói um diálogo entre duas "personagens" com essas diferentes abordagens da ação política: uma democrata deliberativa e uma ativista. Um diálogo entre elas é útil porque suas receitas para a boa cidadania divergem em alguns aspectos. Com esse exercício, pretendo apontar algumas das limitações de, pelo menos, algumas visões sobre as normas deliberativamente democráticas, principalmente se são entendidas como práticas orientadoras nas democracias existentes, em que as desigualdades estruturais estão na base de significativas injustiças ou males sociais. Ao mesmo tempo, pretendo sublinhar algumas das virtudes de práticas políticas não deliberativas para a crítica democrática. As "personagens" da democrata deliberativa e da ativista são construídas por mim como tipos ideais. Muitos teóricos políticos e cidadãos certamente simpatizam com ambos, e as posições costumam se alternar e se misturar no mundo político.

Da forma como estabeleço sua personagem, a democrata deliberativa afirma que as partes do conflito político devem deliberar entre si e, por meio de argumentação razoável, tentar chegar a um acordo sobre as políticas que seja satisfatório para todos. A ativista desconfia das exortações à deliberação por acreditar que, no mundo real da política, onde as desigualdades estruturais influenciam procedimentos e resultados, processos democráticos que parecem cumprir as normas de deliberação geralmente tendem a beneficiar os agentes mais poderosos. Ela recomenda, portanto, que aqueles que se preocupam com a promoção de mais justiça devem realizar principalmente a atividade de oposição crítica, em vez de tentar chegar a um acordo com quem sustenta estruturas de poder existentes ou delas se beneficia.

No diálogo que eu construo, as afirmações da democrata deliberativa, de que a ativista visa apenas promover um interesse parcial, não parecem um ponto de vista razoável. Depois de responder, em nome da ativista, a essas acusações ouvidas com frequência, examino quatro desafios que ela traz à recomendação de que os cidadãos responsáveis devem seguir as normas da democracia deliberativa como a melhor forma de envolvimento político. Considero os primeiros desafios mais fáceis para a democrata deliberativa responder do que os últimos.

O objetivo dessa dialética não é recomendar um lado em detrimento do outro, porque acho que ambas as abordagens são válidas e necessárias para uma 
prática democrática que vise promover a justiça. Estabelecer uma relação crítica entre as abordagens dessa forma, no entanto, ajuda a fazer uma advertência sobre a tentativa de colocar em prática os ideais da democracia deliberativa em sociedades com desigualdades estruturais. Esse diálogo também revela tensões que não podem ser completamente resolvidas entre as duas posições.

\section{As personagens}

No esforço para associar às personagens uma sensação corporificada, atribuí pronomes de gênero específicos a cada uma delas. Essa decisão revela um dilema perturbador: elas devem ser ambas do sexo masculino, ambas do sexo feminino ou um homem e uma mulher? Decidir que uma deve ser homem e a outra, mulher só aumenta o dilema: qual delas deve ser o quê? Ao experimentar cada opção, descubro que minha atribuição evoca estereótipos indesejáveis de qualquer maneira. Se o democrata deliberativo for homem, essa posição parece carregar o peso adicional da racionalidade e da calma, e a correspondente ativista feminina parece volúvel e movida principalmente pela paixão. Apesar do risco que permanece de estereotipar o ativista fazendo-o parecer agressivo, decidi tornar a democrata deliberativa uma mulher e o ativista, um homem, pois, pelo menos essa atribuição associa mais a mulher ao poder.

Para os propósitos deste ensaio, entendo a democracia deliberativa como uma visão normativa das bases da legitimidade democrática e uma receita de como os cidadãos devem engajar-se politicamente. A melhor e mais adequada maneira de conduzir a ação política, influenciar e tomar decisões públicas é a deliberação pública. Na deliberação, as partes do conflito, da divergência e da tomada de decisões propõem soluções para seus problemas coletivos e oferecem razões para elas, criticam as propostas e as razões umas das outras e estão abertas a ser criticadas. A democracia deliberativa difere de algumas outras atitudes e práticas na política democrática por exortar os participantes não apenas a se preocuparem com seus próprios interesses, mas a ouvir e levar em conta os interesses dos outros, desde que sejam compatíveis com a justiça. Práticas da democracia deliberativa também têm o objetivo de suspender a influência das diferenças de poder nos resultados políticos, pois o acordo entre os deliberadores deve ser alcançado com base no argumento, e não como resultado de ameaça ou força.

A teoria da democracia deliberativa expressa, portanto, um conjunto de ideais normativos, segundo o qual os processos políticos reais são avaliados 
e geralmente considerados insuficientes. As decisões políticas devem ser tomadas por meio de processos que envolvam todas as partes potencialmente afetadas ou seus representantes em um processo de deliberação pública. Os deliberadores devem apelar à justiça e apresentar as razões para suas propostas em termos que consideram que os outros devam aceitar. Fazer isso exclui a afirmação do simples interesse parcial ou a tentativa de obrigar a aceitação por meio de ameaças e sanções.

Porém, da forma como a construo, a personagem da democrata deliberativa não apenas encontra, nos ideais da democracia deliberativa, meios para criticar processos políticos, mas também defende processos e ações para implementar procedimentos deliberativos na democracia realmente existente, com todo o seu conflito, divergências e desigualdade econômica, social e política. A democrata deliberativa considera que a melhor maneira de limitar a dominação política e a pura imposição do interesse parcial, e promover maior justiça social por meio de políticas públicas, é fomentar a criação de espaços e processos de deliberação entre elementos distintos e discordantes na comunidade política. Sendo assim, ela atribui várias disposições ao bom cidadão. A cidadã politicamente engajada que quer promover a justiça social procura criticar e debater com aqueles de quem discorda ou com quem seus interesses inicialmente se chocam em situações públicas, em que tenta convencer os outros de que algumas políticas ou interesses têm consequências ou aspectos injustos ou maléficos. Mediante argumentação crítica aberta ao ponto de vista dos outros, ela tem como objetivo chegar a conclusões políticas livremente aceitáveis por todos os envolvidos.

Assim como a democrata deliberativa, o ativista apresenta sua postura como modelo de virtude cidadã. Ele está comprometido com justiça social e valor normativo, e com a ideia de que pessoas politicamente responsáveis devem tomar medidas concretas para promovê-los. Também acredita que o funcionamento normal das instituições econômicas e políticas da sociedade em que ele se situa gera ou reproduz problemas profundos - algumas leis ou políticas têm efeitos injustos, estruturas sociais e econômicas causam injustiça, animais não humanos e coisas são impropriamente ameaçados, e assim por diante. Uma vez que as regras e as práticas comuns dessas instituições tendem a perpetuar esses problemas, não podemos corrigi-los dentro dessas regras. $\mathrm{O}$ ativista se opõe a ações ou políticas específicas de instituições públicas ou privadas, bem como a sistemas de políticas ou ações, e quer que 
sejam mudados. Às vezes, também exige políticas e ações concretas para reduzir injustiças ou males.

Além de ser motivado por uma paixão pela justiça, o ativista também é movido, muitas vezes, por raiva ou frustração com o que julga ser a intransigência das pessoas que estão no poder nas instituições existentes. Segundo ele, elas se comportam com arrogância e indiferença para com as injustiças que o ativista acha que elas perpetuam ou categoricamente negam, racionalizando como sendo benéficas suas decisões e as instituições às quais servem. Uma vez que muitos dos seus concidadãos são ignorantes em relação a esses males institucionais ou os aceitam com indiferença ou resignação, o ativista acredita que é importante expressar indignação diante da injustiça continuada, para motivar os outros a agir.

Normalmente, o ativista evita a deliberação, especialmente a que acontece com pessoas brandindo poder político ou econômico e representantes oficiais das instituições que ele acredita perpetuarem injustiças ou males. Acha risível a sugestão de que ele e seus companheiros devem se sentar com aqueles a quem ele critica e cujas políticas combate, para elaborar um acordo por meio de argumentos racionais que todos possam aceitar. Autoridades poderosas não têm motivo para se sentar com ele e, mesmo que concordassem em deliberar, teriam poder de direcionar injustamente o rumo da discussão. Assim, o ativista opta por outra ação que considera mais eficaz para transmitir suas críticas e promover os objetivos que ele acredita corretos: piquetes, panfletagem, guerrilha, manifestações de rua grandes e estrondosas, ocupações e outras formas de ação direta, como boicotes. Com frequência, os ativistas fazem barulho em público do lado de fora quando a deliberação supostamente vai acontecer no interior. ${ }^{2}$ Às vezes, invadem os locais de deliberação e interrompem o que está em curso, desfraldando bandeiras, jogando bombas de mau cheiro ou correndo e gritando pelos corredores. Outras vezes, estão convencidos de que uma instituição produz ou perpetua tantos problemas que o mais apropriado moralmente é tentar parar seu funcionamento, por exemplo, bloqueando entradas.

As táticas moralmente aceitáveis são muito discutidas pelos ativistas. Eles devem ser estritamente não violentos, e o que significa exatamente ser não violento? Ser irritante e insultante é aceitável ou o ativista deve ser respei-

Além da deliberação, Michael Walzer (1999) oferece uma lista útil de atividades políticas, algumas das quais caracterizam o ativista. 
toso? É aceitável destruir ou danificar propriedade, desde que não se firam pessoas ou animais? Não desejo entrar nesses debates aqui. Para efeitos dessa caracterização, pressuponho que o ativista acredite que a violência intencional direcionada a outros não é moral nem politicamente aceitável, mas que ele tem direito de se defender fisicamente se for atacado fisicamente. Vou pressupor que o ativista rejeite táticas que causem intencionalmente danos graves à propriedade, tais como colocar bombas ou incendiar. Formas menos prejudiciais de destruir ou quebrar, principalmente como subprodutos de ações de protesto, não precisam ser condenadas.

\section{O julgamento deliberativo do ativismo}

As teorias da democracia deliberativa raramente mencionam as atividades políticas, como as que eu considerei típicas do ativismo e, portanto, não podemos deduzir delas uma visão direta do grau em que a virtude política, como é entendida pelos democratas deliberativos, opõe-se à virtude política como eu a caracterizei para o ativista. Contudo, sabemos que muitos participantes políticos responsáveis costumam condenar os ativistas, considerando-os niilistas irracionais que trazem uma imagem ruim para boas causas.

Do ponto de vista dos princípios da democracia deliberativa, que razões eles poderiam ter? Podemos reconstruir dois tipos de razões, eu sugiro. Alguns, que se consideram guiados por normas da democracia deliberativa, podem dizer que os ativistas se envolvem na política de grupos de interesse em vez de orientar seu compromisso a princípios que todos possam aceitar. Também podem dizer que a postura do ativista é simplesmente não razoável. Aqui, examino essas críticas possíveis ao ativismo do ponto de vista da democracia deliberativa e respondo a elas em nome do ativista.

Da forma como a construo para os propósitos deste encontro, a democrata deliberativa julga a abordagem da democracia assumida pelo ativista pouco diferente da política de grupos de interesse, baseada em pressão, que ela considera que deve ser superada para se alcançar um acordo viável e resultados legítimos em termos de políticas. Uma abordagem da política focada nos grupos de interesse incentiva as pessoas a organizar grupos para promover determinados fins através da política e de políticas públicas, pressionando ou bajulando os formuladores dessas políticas para atender àqueles interesses. Fazendo lobby, comprando propagandas políticas, contribuindo com fundos para partidos e candidatos e mobilizando votos a favor ou contra candidatos que defendam 
posições sobre determinadas questões, os grupos de interesse promovem seus objetivos e derrotam seus oponentes. Eles não sentem nenhuma obrigação de discutir as questões com aqueles com quem seus interesses se chocam para chegar a um acordo que todos possam aceitar. Simplesmente visam conquistar o máximo para seu grupo e, para isso, exercem política baseada em poder.

A essa acusação, o ativista responde que sua postura é diferente da simples defesa de interesses, porque ele está comprometido com uma causa universalista e não parcial. Há uma diferença importante, segundo ele, entre interesse próprio ou de grupo e o interesse em reparar males e injustiças. O bom ativista cidadão geralmente não é motivado por ganhos pessoais nem pelo ganho de grupos que defende em detrimento, injustamente, de outros. Ele sacrifica seu tempo, seu avanço profissional e seu dinheiro em nome de causas com as quais está comprometido; busca, de fato, fazer pressão, usar o poder da ação coletiva, da interrupção e do constrangimento para realizar transformações que apontem no sentido de mais justiça. O poder que ele e seus companheiros exercem nas ruas, no entanto, costuma ser um mero Davi diante do Golias do poder exercido por atores estatais e corporativos a cujas políticas ele se opõe e as quais pretende mudar. A democrata deliberativa que pensa que o poder pode ser atenuado pela suavidade das salas de reuniões é ingênua.

Embora desconfie da alegação de que deveria tomar parte da deliberação com os poderosos agentes que ele acredita perpetuarem injustiças e males ou com quem os apoia, o ativista não rejeita completamente a discussão. A difusão e a troca de informações e ideias são uma parte importante de seu trabalho político, tanto dentro de suas organizações ativistas quanto, mais amplamente, entre outros cidadãos a quem pretende convencer de que há graves males e injustiças contra os quais deveriam protestar e resistir. Quando as instituições sociais, econômicas e políticas produzem desigualdades estruturais injustas e outros males sociais e ambientais graves, insiste o ativista, é importante que os cidadãos tentem evitar a cumplicidade com o funcionamento dessas instituições. Atividades de protesto, boicote e interrupção são as mais apropriadas para fazer com que os cidadãos pensem seriamente sobre o que até então podem ter considerado normal e aceitável. Atividades de deliberação, ao contrário, tendem mais a conferir legitimidade a instituições existentes e efetivamente silenciar a verdadeira dissidência.

A democrata deliberativa pode alegar que a postura do ativista não é razoável. O engajamento político razoável, segundo essa visão, consiste na vontade 
de ouvir aqueles que se acredita estarem errados, para demandar suas razões e apresentar argumentos para convencê-los a mudar seus pontos de vista. Na maior parte do tempo, o ativista declina a interação com as pessoas de quem discorda. Em vez de basear-se na razão, de acordo com essa democrata deliberativa o ativista se baseia em apelos emocionais, palavras de ordem, ironia e táticas de interrupção para protestar e fazer suas reivindicações.

Portanto, na vida política de muitas democracias, é comum rotular uma postura ativista de irracional e até mesmo de "extremista". Podem-se interpretar esses próprios rótulos generalizantes como uma jogada de poder cuja função é descartar todas as afirmações que questionarem algo básico sobre as instituições existentes e os termos em que elas apresentam alternativas políticas. É importante, portanto, considerar a resposta ativista à acusação que lhe fazem, de ser um extremista irracional: essa acusação se baseia em uma visão muito mais estreita do que é razoável.

Com "razoável", refiro-me a ter um entendimento de uma gama de alternativas em termos de crença e ação e a julgar de maneira refletida para decidir entre elas. A pessoa razoável, portanto, também é capaz de justificar suas afirmações e ações aos outros e está disposta a isso. Da forma como construí sua postura, o ativista é uma pessoa de princípios e razoável nesse sentido. Ele reflete sobre alguns dos problemas que acometem pessoas e coisas não humanas e tem uma visão sobre algumas das causas sociais desses problemas que acredita serem alteráveis. Ele reflete sobre meios alternativos para chamar a atenção a eles e conclama outros para que ajudem a corrigi-los, e geralmente está bastante preparado para justificar o uso de meios específicos em ocasiões específicas, tanto a seus companheiros quanto a outros, por exemplo, repórteres de televisão. Embora seus princípios muitas vezes o levem a protestar do lado de fora ou a interromper as reuniões de pessoas poderosas de quem discorda, uma de suas principais razões para esse protesto é conscientizar um público mais amplo dos problemas institucionais e convencer esse público a se juntar a ele para pressionar pela mudança nas instituições. Apesar de não ser deliberativa, no sentido de participar da apresentação ordenada de argumentos, a maioria dos engajamentos políticos ativistas pretende comunicar ideias específicas a um público amplo. Usam palavras de ordem, humor e ironia para isso porque os argumentos discursivos, apenas, não têm muita probabilidade de chamar atenção nem de inspirar ação (ver Young, 2000, cap. 2). 
No mundo real da política, algumas pessoas niilistas e destrutivas se manifestam e protestam a partir da raiva cega ou porque sentem prazer na destruição, mas essa postura niilista descreve poucos ativistas. A maioria é mais autoconsciente do que outros atores políticos quanto às boas razões para fazer o que faz e disciplinar seus companheiros a seguir regras em suas ações coletivas. A atitude retórica comum tomada pelos poderes oficiais para pintar toda a ação de protesto com o piche do "extremismo" deve ser combatida por qualquer pessoa comprometida com a justiça social e a comunicação razoável.

Agora que o ativista respondeu à suspeita da democrata deliberativa de que não vale a pena falar com ele, podemos ouvir a crítica que ele faz às recomendações deliberativas para o envolvimento político e a virtude cidadã. Apresentarei esses desafios em quatro passos, dando à democrata deliberativa a oportunidade de responder a cada um deles.

\section{Os procedimentos deliberativos são excludentes}

Segundo o ativista, exortar os cidadãos a participar de discussões respeitosas com outros de quem discordam é uma boa recomendação para o mundo ideal que a democrata deliberativa teoriza, onde todos estão incluídos e são iguais politicamente uns aos outros. Contudo, este não é o mundo real da política, onde as elites poderosas que representam segmentos sociais estruturalmente dominantes têm uma influência significativa sobre processos e decisões políticos.

A deliberação, às vezes, ocorre no mundo real. Autoridades e funcionários se reúnem o tempo todo para elaborar acordos. Suas reuniões costumam ser bem organizadas, com procedimentos estruturados, e quem conhece as regras costuma conseguir fazer avançar seus objetivos por meio delas, fazendo propostas e apresentando as razões para elas, examinadas e avaliadas criticamente pelos outros, os quais, por sua vez, apresentam suas próprias razões. A deliberação, diz o ativista, é uma atividade de salas de reuniões, comissões parlamentares e, às vezes, até dos próprios parlamentos. As elites exercem seu poder, em parte, por meio da gestão de ambientes deliberativos. Entre si, participam do debate sobre as políticas que sustentarão seu poder e promoverão seus interesses coletivos. A entrada nesses ambientes deliberativos geralmente é controlada de forma bastante rígida, e os interesses de muitos dos afetados pelas decisões tomadas neles muitas vezes não têm voz 
nem representação. Além disso, os trabalhos dessas reuniões não são abertos à observação geral e não há registro público. Observadores e imprensa só comparecem por convite. A deliberação é essencialmente uma atividade das elites políticas que se tratam com respeito cordial e tentam resolver suas diferenças. Na medida em que a deliberação é excludente nesse sentido e as decisões tomadas nesses órgãos deliberativos sustentam e perpetuam a desigualdade estrutural ou têm outras consequências injustas e maléficas, diz o ativista, é errado recomendar a deliberação a bons cidadãos comprometidos com o aprofundamento da justiça social. Nessas circunstâncias de desigualdade estrutural e poder excludente, os bons cidadãos deveriam estar protestando do lado de fora dessas reuniões, chamando a atenção do público para os pressupostos usados nelas, para o controle exercido e para as limitações ou problemas geradas por seus resultados. Eles deveriam usar o poder de constranger e expor para pressionar os deliberadores a ampliar sua agenda e incluir a atenção a mais interesses. Enquanto os procedimentos de reuniões exercerem poder excludente em nome dos interesses das elites e contra os da maioria dos cidadãos, os cidadãos politicamente engajados que se preocupam com a justiça e a preservação ambiental têm razões até mesmo para as ações destinadas a impedir ou interromper as deliberações.

Muitas dos milhares de pessoas que encheram as ruas de Seattle em dezembro de 1999, parece-me, tinham essa visão da relação entre deliberação e protesto. Chefes de Estado ou outras autoridades importantes vieram do mundo todo a uma reunião da Organização Mundial do Comércio (OMC) para deliberar e tentar chegar a um acordo sobre uma nova rodada de regras comerciais globais. Os manifestantes criticaram a reunião, e muitos pensavam que ela deveria simplesmente ser suspensa. Eles protestaram contra os métodos excludentes da OMC, contra o fato de os trabalhos de sua comissão serem fechados e de que a própria reunião de Seattle não fosse pública. Alegavam que a OMC é uma ferramenta do poder das grandes empresas transnacionais e que suas deliberações dão pouca atenção aos efeitos do regime de livre comércio sobre os cidadãos comuns, principalmente as pessoas mais pobres do mundo. As deliberações da OMC não são legítimas e a agenda da organização é moralmente errada. Enquanto escrevo isto, alguns dos meus concidadãos se preparam para protestar contra deliberações semelhantes no acordo de livre comércio nas Américas. Não apenas as reuniões são excludentes, mas nem mesmo o documento que elas irão 
discutir é público. Não há alternativa ao protesto e à interrupção, pensa o ativista, quando as decisões que afetam tantas pessoas são tomadas por tão poucos e quase em segredo.

A defensora da democracia deliberativa como receita para os processos políticos e para o comportamento de bons cidadãos tem uma resposta fácil a essa crítica à deliberação. Ela concorda com muitas coisas que o ativista diz. Sendo excludentes e não públicos, os trabalhos das reuniões de elite não são democráticos, mesmo que sejam deliberativos. As normas da democracia deliberativa não pedem apenas discussão entre partes que usem só a força do argumento e tratem umas às outras como iguais; elas também exigem divulgação pública, responsabilização e inclusão. ${ }^{3}$ Para ser democraticamente legítimas, políticas e ações decididas por meio de deliberação devem incluir a representação de todos os interesses e perspectivas afetados. As deliberações nesses organismos inclusivamente representativos deveriam ser públicas em todos os sentidos. As pessoas que falam e votam nesses ambientes deliberativos, por fim, devem ser responsáveis por suas opiniões e decisões perante os seus concidadãos. A democrata deliberativa provavelmente irá se juntar ao ativista para protestar do lado de fora de reuniões de deliberação que sejam excludentes e privadas. Ela exorta o ativista a participar de sua exigência de deliberações cujos processos sejam públicos, passíveis de responsabilização e inclusivos, e apoia o ativista ao considerar ilegítimos os processos deliberativos que não cumpram essas condições. Ela pode considerar os protestos ativistas como um meio saudável para o aprofundamento da democracia e para criar ambientes abertos e inclusivos de democracia deliberativa.

\section{Inclusão formal não é suficiente}

A crítica aos processos políticos de discussão e tomada de decisões que incluam apenas os já membros e os poderosos, e aconteçam a portas fechadas, é frequente e costuma ser eficaz na política democrática. Em resposta a essas críticas, os organismos deliberativos oficiais, por vezes, tomaram medidas para tornar seus processos mais públicos e inclusivos. Abrem suas portas à observação por parte da imprensa e dos cidadãos, bem como pu-

Amy Gutmann e Dennis Thompson insistem em critérios de divulgação pública e responsabilização em seu livro, Democracy and disagreement (Gutmann eThompson, 1996). Embora certamente concordem em que a inclusão é um critério, eles não fazem dela um princípio separado. Sobre razões para fazê-lo, ver Young (1999). 
blicam relatórios de seus trabalhos e avaliações de suas operações. Alguns organismos oficiais legislativos e de outros tipos já discutiram e implementaram medidas destinadas a abrir suas sedes a uma maior diversidade de representantes, incluindo regulamentação do financiamento de campanha, reforma do processo eleitoral ou mesmo cotas nas listas partidárias para grupos sub-representados. Nos Estados Unidos, nos últimos 30 anos, as normas de inclusão e divulgação pública têm sido levadas mais a sério do que antes. Órgãos públicos e até mesmo algumas instituições privadas poderosas fazem audiências para discutir propostas de políticas, nas quais os membros do público são convidados a dar seu testemunho. Influenciadas pelas ideias de James Fishkin, algumas autoridades locais e organizações não governamentais têm promovido "júris cidadãos", que pretendem ser amplamente representativos do perfil do eleitorado (Fishkin, 1995). Os membros desses painéis ouvem e questionam candidatos a cargos políticos sobre temas, e deliberam entre si, muitas vezes também recebendo contribuições por telefone e e-mail de cidadãos que acompanham os trabalhos pelo rádio. Muitos estudiosos da democracia têm elogiado o processo amplamente participativo de deliberação pública que o estado do Oregon realizou na década de 1990, no processo de reestruturação de seu programa de saúde para pessoas de baixa renda. Outro exemplo notável de esforço heroico para tornar inclusiva a deliberação pública é o processo de consulta que o governo da África do Sul fez para discutir a nova constituição que entrou em vigor em 1996. Os encarregados da elaboração da constituição não só solicitaram comentários sobre o projeto por correio e email, mas também realizaram reuniões públicas para quem não conseguisse lê-lo, explicando o seu conteúdo aos participantes e solicitando opiniões.

A democrata deliberativa apoia medidas como essas. Ela acha que o bom cidadão deveria defender vigorosamente maneiras criativas de expandir a divulgação pública das deliberações sobre os problemas e propostas de políticas, e torná-las inclusivas. Se eles tiverem a oportunidade de participar desse tipo de processo deliberativo consultivo, devem fazê-lo, e, se forem convidados a ajudar a formulá-los, devem aceitar.

O ativista é mais desconfiado, mesmo em relação a esses processos deliberativos que afirmam dar oportunidade de expressar opiniões em um processo deliberativo a todos os afetados pelas políticas projetadas ou, pelo menos, a representantes de todos eles. Em uma sociedade estruturada por 
profundas desigualdades sociais e econômicas, ele acredita que os processos deliberativos formalmente inclusivos ativam, apesar disso, vieses estruturais pelos quais os atores mais poderosos e socialmente favorecidos têm maior acesso ao processo deliberativo e, portanto, conseguem dominá-lo com seus interesses e perspectivas.

Em condições de desigualdade estrutural, os processos normais de deliberação frequentemente restringem, na prática, o acesso aos agentes com mais recursos, conhecimentos ou conexões com quem detém maior controle sobre o fórum. Já conhecemos as muitas manifestações dessa efetiva exclusão da deliberação. Onde o rádio e a televisão são os principais fóruns para ampliar a deliberação, por exemplo, os cidadãos precisam de dinheiro ou conexões para obter tempo de transmissão. Mesmo quando se anuncia uma série de audiências públicas para tratar de um tema, as pessoas que talvez quisessem falar nelas precisam ficar sabendo delas, ser capazes de organizar seus horários de trabalho e do cuidado com os filhos para poder participar, conseguir chegar até lá e ter conhecimento suficiente do processo de audiência para participar. Cada uma dessas habilidades está presente de forma desigual entre membros de uma sociedade.

Alguns já argumentaram que esse acesso e essa participação diferenciados caracterizaram ambos os processos deliberativos públicos ostensivamente inclusivos que eu citei acima: o processo do Medicaid no Oregon e as deliberações sobre a constituição sul-africana. No primeiro caso, os participantes do processo de consulta acabaram sendo, em grande parte, pessoas brancas, de classe média, saudáveis, embora o programa fosse voltado especificamente para as pessoas de baixa renda. Uma grande quantidade de cidadãos da África do Sul entendia muito pouco sobre o significado de uma Constituição, ou suas vidas estavam muito ocupadas pela sobrevivência para se envolverem nesse processo deliberativo.

Desse modo, o ativista defende que os cidadãos que se preocupam com a justiça deveriam continuar a criticar, de fora, os processos de deliberação pública, mesmo quando estes têm regras formais que visam gerar uma ampla participação. Na medida em que as desigualdades estruturais na sociedade operam de forma eficaz para restringir o acesso a esses processos deliberativos, suas deliberações e conclusões não são legítimas. Cidadãos responsáveis devem permanecer, pelo menos parcialmente, do lado de fora, protestando contra o processo, a agenda e os resultados desses trabalhos e 
se manifestando contra as relações subjacentes de privilégio e desvantagem que os condicionam. O objetivo desses cidadãos deve ser falar em nome dos realmente excluídos e tentar usar táticas como greves, boicotes e manifestações que interrompam o processo, para pressionar esses organismos a agir de forma que responda às necessidades e aos interesses dos efetivamente excluídos. Se participarmos desses processos formalmente inclusivos, diz o ativista, ajudaremos a lhes conferir uma legitimidade que não merecem e deixaremos de falar por aqueles que permanecem na condição de outsiders.

As recentes reuniões da OMC são outro exemplo de tentativa de fazer um processo mais includente que a maioria dos ativistas presentes rejeitava como ilegítima. Em resposta a críticas antecipadas à organização como fórum excludente, dominado por interesses corporativos a serviço das economias do hemisfério norte, alguns de seus funcionários organizaram às pressas uma reunião para o dia anterior ao encontro oficial da OMC, para a qual foram convidados representantes das organizações não governamentais (ONGs). Muitos ativistas consideraram esse gesto uma tentativa absurda de cooptar e amortecer uma oposição à reunião da OMC, oposição esta que, mesmo antes de começar, tinha sido muito eficaz em levar as questões da transparência e da desigualdade global diante de um público mundial; eles fizeram manifestações fora das reuniões das ONGs. Além disso, alguns dos representantes de ONGs que decidiram participar da reunião ficaram muito decepcionados. Eles encontraram a agenda já decidida e se viram ouvindo passivamente o diretor da OMC, o secretário de comércio dos Estados Unidos e outras figuras poderosas, e tiveram um tempo mínimo para questionar as falas deles ou fazer as suas próprias. Pelo que parece, ao tentar reformar os processos políticos para que sejam mais publicamente inclusivos, os agentes da exclusão passam longe de dar acesso a voz, de fato, àqueles menos privilegiados nas estruturas sociais. Tendo em conta essas realidades, diz o ativista, a postura mais responsável para o cidadão que se preocupa com a justiça é expor esse poder de manipulação e expressar as demandas legítimas daqueles que sofrem sob injustiças estruturais, independentemente de os poderosos os ouvirem.

A democrata deliberativa concorda com a argumentação do ativista e com sua crítica à maneira como as desigualdades estruturais efetivamente limitam o acesso de algumas pessoas a ambientes deliberativos formalmente inclusivos. Diferentemente do ativista, no entanto, ela acha que o cidadão responsável 
deve participar e discutir com aqueles que formatam e implementam esses ambientes para convencê-los de que eles devem dedicar reflexão e recursos a atividades que irão tornar esses espaços mais inclusivos e representativos de todos os interesses e perspectivas potencialmente afetados pelo resultado das discussões sobre políticas. Em uma comunidade política que se diz comprometida com a democracia, deve ser possível convencer muitos membros de um público deliberativo formalmente inclusivo de que pode ser preciso tomar medidas especiais para proporcionar voz e representação a segmentos da sociedade submetidos a desvantagens estruturais. Protestar e fazer exigências do lado de fora pode ser uma forma eficaz de chamar a atenção para as injustiças que demandam solução, diz a democrata deliberativa, mas, por si só, não impulsiona a transformação institucional positiva que produziria maior justiça. Aqueles que acreditam que essa mudança é necessária devem entrar nos procedimentos deliberativos com aqueles que lhes são indiferentes ou hostis, em um esforço para convencer um público democrático de que estão certos. ${ }^{4}$

Os dois primeiros desafios do ativista trataram da divulgação pública e do caráter inclusivo do público deliberativo, e não dos termos e do conteúdo das deliberações. Até agora, as perspectivas da democrata deliberativa e do ativista são bastante próximas nas questões de processos políticos moralmente legítimos, já que ambos criticam exclusões formais e reais em relação às deliberações. A diferença entre eles pode se reduzir a quão otimistas eles são em relação à possibilidade de persuadir agentes políticos de que há injustiças estruturais, e a solução para elas deve ter a concordância de um público deliberativo inclusivo. Ao nos voltarmos à analise de questões relativas aos termos e ao conteúdo das deliberações, no entanto, vemos mais divergência entre a democrata deliberativa e o ativista.

\section{Alternativas restringidas}

Suponhamos que, por alguma combinação de agitação ativista e persuasão deliberativa, surjam alguns ambientes deliberativos que representem aproximadamente todos os afetados pelo resultado de certas decisões a respeito de políticas. Considerando-se o mundo de desigualdade estrutural tal como o conhecemos, o ativista acredita que essas circunstâncias serão raras, na melhor das hipóteses, mas está disposto a cogitar a possibilidade

Esta é a posição que eu defendo nos primeiros capítulos de Inclusion and democracy (Young, 2000). 
para os fins deste debate. O ativista permanece desconfiado da exortação que a democrata deliberativa faz para que participe de discussões racionais e críticas com pessoas de quem ele discorda, mesmo na suposição de que o público no qual ele se engaja nessa discussão realmente inclua a diversidade de interesses e perspectivas potencialmente afetados pelas políticas. Isso porque ele percebe que as estruturas sociais e econômicas existentes criaram restrições inadmissíveis aos termos da deliberação e sua agenda.

Problemas e divergências no mundo real da política democrática aparecem e são abordados contra o pano de fundo de uma determinada história e sedimentação da desigualdade estrutural injusta que, diz o ativista, ajuda a estabelecer prioridades de agenda e restringe as alternativas que os atores políticos podem cogitar em suas deliberações. Quando é assim, tanto a agenda deliberativa quanto as restrições institucionais que ela reflete devem ser alvo de críticas, protestos e resistência. ${ }^{5}$ Sentar à mesa para se reunir com representantes desses interesses tipicamente servidos por relações institucionais existentes e discutir como lidar de forma mais justa com essas questões que pressupõem aquelas relações institucionais confere muita legitimidade às instituições e ao processo deliberativo. Coopta a energia dos cidadãos comprometidos com a justiça, deixando pouco tempo à mobilização de pessoas para combater a partir de fora as restrições institucionais e o processo de tomada de decisões. Assim, o cidadão responsável deve se retirar da aceitação implícita das restrições estruturais e institucionais ao se recusar a deliberar sobre as políticas do lado de dentro. Permitam-me dar alguns exemplos.

Um grupo local que atua politicamente no combate à pobreza participou de muitas formas de agitação e protestos nos anos que antecederam a aprovação da Lei de Responsabilidade Pessoal e Conciliação de Oportunidades de Trabalho (Personal Responsibility and Work Opportunity Reconciliation Act) pelo Congresso dos Estados Unidos, na primavera de 1996. Essa legislação modificou fundamentalmente os termos da política de assistência social e previdência no país. Aboliu direitos à assistência pública pela primeira vez em 60 anos, permitindo que os estados negassem benefícios quando as verbas se esgotassem. A lei exige que os beneficiários da chamada Assistência Temporária a Famílias Carentes trabalhassem em empregos depois de um certo período e permite que os estados variem muito seus programas.

Esta é uma das principais respostas de lan Shapiro às ideia de democracia deliberativa em seu ensaio "Enough of deliberation: politics is about interests and power" (Shapiro,1999). 
Desde a aprovação da legislação, o grupo de combate à pobreza organizou beneficiários e outros que se preocupam com a justiça social para protestar e pressionar o parlamento estadual a aumentar o financiamento para a assistência e incluir, como "atividade de trabalho", o serviço como defensor dos direitos à assistência social em escritórios locais.

Em seu desejo de fazer o melhor pelos clientes da assistência social, o departamento responsável no distrito propõe a criação de um conselho consultivo, com influência significativa sobre a implantação e administração de programas de assistência no município. Eles foram convencidos pelos defensores da democracia deliberativa de que os trabalhos desse conselho deverão responder publicamente e ser organizados de modo a facilitar a discussão séria e a crítica de propostas diferentes. Eles acreditam que a justiça democrática exige que esse órgão seja amplamente inclusivo em relação aos cidadãos do distrito e acham que as deliberações legítimas serão bastante aprimoradas se incluírem os beneficiários e seus defensores no conselho. Sendo assim, convidam o grupo de combate à pobreza a enviar representantes e lhes pedem para indicar representantes dos beneficiários escolhidos entre os membros da organização de defesa dos direitos sociais com a qual trabalham.

Depois de deliberar entre si por algumas semanas, os ativistas dos direitos sociais declinam da participação no conselho. As restrições que as leis federal e estadual impuseram à política de assistência, eles afirmam, impossibilitam administrar uma política de bem-estar social humana. Um conselho desse tipo irá decidir se seria mais justo instalar escritórios locais de assistência aqui ou ali, mas não terá poder para ampliar o número desses escritórios. Eles vão decidir a melhor forma de administrar a assistência no cuidado com as crianças, mas não terão poder para decidir quem é elegível para essa assistência ou o total de verbas para sustentar o programa. As deliberações do conselho de implementação de assistência do distrito enfrentam inúmeras outras restrições que tornarão seus resultados inevitavelmente injustos, de acordo com o grupo ativista. Todos os cidadãos do distrito que concordam em que o marco das políticas é injusto têm a responsabilidade de ficar de fora dessas deliberações e, em lugar delas, pressionar o legislativo estadual para expandir as opções de assistência, fazendo, por exemplo, ocupações no departamento estadual de serviços sociais.

A democrata deliberativa considera essa recusa e essa ação de protesto não cooperativas e contraproducentes. Certamente, é melhor construir a 
forma mais justa de implementar a legislação do que perturbar legisladores e obstruir a rotina de funcionários sobrecarregados. $\mathrm{O}$ ativista responde que é errado cooperar com políticas e processos que presumem restrições institucionais injustas. O problema não é que os formuladores de políticas e as deliberações dos cidadãos não consigam apresentar argumentos, mas que suas premissas iniciais sejam inaceitáveis.

Parece-me que os defensores da democracia deliberativa que acreditam que processos deliberativos são a melhor maneira de conduzir as políticas, mesmo nas condições de desigualdade estrutural que caracterizam as democracias de hoje, não têm resposta satisfatória a essa crítica. Muitos defensores de procedimentos deliberativos parecem não ver problema nas estruturas e restrições institucionais que limitam as alternativas políticas nas democracias reais, defendendo o debate político reflexivo dentro delas para combater tendências irracionais a reduzir as questões a declarações midiáticas e as decisões preferências agregadas. Em sua discussão detalhada sobre os termos da reforma da assistência social em Democracy and disagreement, por exemplo, Amy Gutmann e Dennis Thompson parecem aceitar como dado que as políticas para responder às necessidades das pessoas pobres devem vir na forma de apoio aos pobres, em vez de mudanças na política fiscal, na relação entre investimento público e privado, no emprego em obras públicas e outras formas mais estruturadas de combater a privação e a desigualdade de renda (Guttman e Thompson, 1996, cap. 8) ${ }^{6}$. O inovador fórum de cidadãos de James Fishkin, que deliberava sobre questões nacionais em conexão com a campanha política de 1996, para dar outro exemplo, parecia considerar como dadas todas as restrições fiscais, de poder e institucionais a alternativas de políticas públicas que o Congresso dos Estados Unidos e a grande imprensa pressupunham. Na medida em que essas restrições aceitam como dados padrões existentes de desigualdade de classe, segregação residencial e divisão de gênero no trabalho, a alegação do ativista de que há pouca diferença entre as alternativas debatidas é plausível, e ele sugere que o cidadão responsável não deveria aceitar essas suposições, e sim agitar por uma crítica e uma transformação mais profundas.

A atividade permanente de legislação e implementação de políticas considerará como dadas as instituições existentes e suas prioridades, a menos

Gutmann e Thompson representam, aqui, a discussão sobre políticas relacionadas a essas questões nos Estados Unidos, assim como da opinião pública norte-americana. 
que uma ação articulada de grande porte trabalhe para alterar prioridades e metas. Assim sendo, na maior parte do tempo, a política irá operar sob as alternativas restringidas que são geradas pelas desigualdades estruturais e as sustentam. Se tentar inserir práticas de deliberação em discussões existentes de políticas públicas, a democrata deliberativa será forçada a aceitar a gama de alternativas permitida pelas restrições estruturais existentes. Enquanto, duas décadas atrás, havia poucas oportunidades para os teóricos da democracia deliberativa tentarem influenciar o formato do processo de discussão pública nos Estados Unidos, hoje as coisas mudaram. Algumas autoridades públicas e fundações privadas se convenceram de que a deliberação inclusiva, fundamentada e ampla é boa para a democracia e desejam implementar esses ideais no processo de formulação de políticas. Como essa aplicação deve pressupor alternativas restritas que não podem questionar as prioridades institucionais e as estruturas sociais existentes, a deliberação tem tantas probabilidades de reforçar a injustiça quanto de combatê-la.

Eu acho que a democrata deliberativa não tem uma resposta adequada a esse desafio que não seja aceitar a desconfiança do ativista em relação à implementação de processos deliberativos dentro das instituições que restringem seriamente as políticas alternativas a ponto de, por exemplo, quase impossibilitar que os estruturalmente desfavorecidos proponham soluções para problemas sociais que possam alterar as posições estruturais em que estão situados. Somente se estiverem dispostas a sair do imediatismo da trajetória política já dada, a teoria e a prática da democracia deliberativa poderão responder a esse desafio ativista. A democracia deliberativa deve ajudar a criar ambientes deliberativos inclusivos em que as estruturas sociais e econômicas básicas possam ser examinadas; esses ambientes, na maior parte, devem estar do lado de fora e mesmo oposto aos ambientes correntes da discussão oficial das políticas.

\section{Discurso hegemônico}

A democrata deliberativa responde a esse desafio ativista propondo a criação de fóruns deliberativos afastados do imediatismo de imperativos econômicos e estruturas de poder dados, nos quais representantes de setores sociais diversos possam discutir criticamente esses imperativos e estruturas, visando à reforma do contexto institucional. Mesmo nesse momento, no entanto, o ativista continua desconfiado em relação às práticas deliberativas, 
por mais uma razão que remete às desigualdades estruturais. Ele teme que a maioria dos participantes em um ambiente deliberativo tão reflexivo venha a ser influenciada por um discurso comum que, em si, é produto complexo da desigualdade estrutural. Com "discurso", quero dizer um sistema de histórias e conhecimento especializado difundidos em toda a sociedade, que transmite as generalizações amplamente aceitas sobre como a sociedade funciona, teorizadas nesses termos, bem como as normas sociais e valores culturais a que a maioria das pessoas recorre ao discutir seus problemas sociais e políticos e as soluções propostas. Em uma sociedade com desigualdades estruturais antigas e numerosas, alguns desses discursos são, nos termos derivados de Gramsci, "hegemônicos": a maioria das pessoas na sociedade pensa sobre suas relações sociais nesses termos, seja qual for sua posição nas desigualdades estruturais. Quando esses sistemas discursivos embasam um processo deliberativo, as pessoas podem chegar a um acordo que é, no entanto, pelo menos em parte, condicionado por relações de poder injustas e que, por essa razão, não deve ser considerado um consenso realmente livre. Em alguns de seus trabalhos anteriores, Habermas teorizou sobre esse falso consenso como "comunicação sistematicamente distorcida" (ver Habermas, 1970) ${ }^{7}$. Quando esse discurso hegemônico opera, as partes envolvidas na deliberação podem concordar sobre as premissas, aceitar uma teoria sobre sua situação e apresentar as razões para propostas que os outros aceitam, mas, mesmo assim, as premissas e as condições dessa visão mascaram a reprodução do poder e da injustiça.

Os democratas deliberativos se concentram na necessidade de acordo para dar legitimidade às políticas e teorizam sobre as condições para alcançar esse acordo, mas a ideia de acordo falso ou distorcido parece estar fora dessa teorização. Ao abrir a possibilidade de que algum consenso seja falso e alguma comunicação seja sistematicamente distorcida pelo poder, não estou me referindo a um consenso obtido por meio da exclusão de algumas pessoas afetadas ou que é extorquido por meio de ameaça e coerção. O fenômeno da hegemonia ou da comunicação sistematicamente distorcida é mais sutil do que isso. Refere-se à forma como a estrutura conceitual e normativa dos

À luz do fato de que Habermas contribuiu muito para as teorias contemporâneas da ideologia ou comunicação distorcida, é surpreendente e decepcionante que a sua própria teoria da democracia deliberativa, como é expressa em Between facts and norms, quase não dê espaço à teorização da comunicação distorcida e seus efeitos sobre a legitimidade dos resultados políticos (Habermas, 1996). 
membros de uma sociedade é profundamente influenciada por premissas e termos de discurso que dificultam pensar criticamente sobre os aspectos de suas relações sociais ou possibilidades alternativas de institucionalização e ação. A teoria e a prática da democracia deliberativa não têm ferramentas para levantar a possibilidade de que as deliberações possam ser fechadas e distorcidas dessa forma. Ela carece de uma teoria, chamemos assim, da ideologia, bem como de uma visão da genealogia dos discursos e sua maneira de ajudar a constituir a forma como as pessoas veem a si mesmas e seu mundo social. Para a maioria dos democratas deliberativos, o discurso parece ser mais "inocente".

A teoria deliberativa de James Bohman é uma importante exceção a essa afirmação. No centro da visão de Bohman sobre as normas da deliberação pública está uma preocupação em identificar formas nas quais as desigualdades estruturais operam efetivamente para bloquear a influência política de alguns, enquanto ampliam a dos outros, mesmo quando se aplicam as garantias formais da igualdade política. Sem distingui-las do modo que eu fiz acima, Bohman analisa como as formas de exclusão e dominação da agenda que discuti até agora inibem a deliberação pública na qual todos os interesses e perspectivas são devidamente considerados. Um teste importante da legitimidade deliberativa de um processo político, argumenta ele, é o grau em que os grupos não só conseguem que suas opiniões sobre questões e propostas já em discussão sejam ouvidas, mas também são capazes de iniciar a discussão de problemas e propostas.

Ao analisar como discussões públicas reais podem ficar aquém das exigências normativas da discussão democrática legítima, Bohman invoca a noção de comunicação distorcida ou ideologia. Esse nível da influência da desigualdade estrutural sobre a discussão pública é o mais insidioso por ser o menos evidente a todos os participantes. Está relacionado ao marco conceitual e imagético da discussão, que muitas vezes contém falsificações, preconceitos, incompreensões e até mesmo contradições que passam sem ser percebidos nem criticados, em grande parte porque coincidem com os interesses hegemônicos ou refletem as realidades sociais existentes como se fossem inalteráveis. Por exemplo, um discurso pode distorcer a comunicação por meio de uma retórica que apresente como universal uma perspectiva da experiência ou a sociedade derivada de uma posição social específica (ver Bohman, 1996, esp. cap. 3; ver também Bohman, 2000). 
Apresentarei alguns exemplos de discursos hegemônicos que podem gerar falso consenso. O primeiro vem de discursos sobre a pobreza e as formas de combatê-la por meio de políticas públicas. Apesar de debates amplos e vigorosos sobre as causas e as soluções para a pobreza, tanto nos Estados Unidos quanto, cada vez mais, em outras partes do mundo, há um novo consenso importante sobre muitos termos do debate. Parece haver um consenso amplo de que a pobreza deve ser conceituada como uma função do fracasso dos indivíduos em desenvolver várias habilidades e capacidades necessárias para a inclusão nos mercados de trabalho modernos. Há muita divergência sobre até onde a responsabilidade por esse fracasso deve ser atribuída a indivíduos e suas famílias ou situada em instituições sociais de educação, serviço social ou desenvolvimento econômico. No entanto, é desnecessário dizer que essa política antipobreza deve acabar por transformar os indivíduos para melhor adequá-los às estruturas contemporâneas de emprego assalariado. Quase não há outra maneira de pensar sobre política para a pobreza do que como uma política para o mercado de trabalho.

Debates internacionais sobre emissões de gases do efeito estufa, para dar outro exemplo, contêm um forte desacordo sobre se e como essas emissões devem ser reduzidas e como os fardos de sua redução devem ser distribuídos em todo o mundo. Os países industriais avançados, mais ricos, devem ser obrigados a reduzir as emissões em proporção maior do que os países menos desenvolvidos? Os mercados de direitos de poluição são políticas úteis? Os governos devem subsidiar o desenvolvimento de tecnologias "verdes" para a produção industrial e o transporte privado? Esses debates ocorrem no âmbito de termos de discussão que só os ambientalistas marginalizados questionam. As discussões pressupõem que as economias de qualquer sociedade desenvolvida devam depender muito da queima de combustíveis fósseis e que um alto padrão de vida envolva edifícios com ar condicionado e muitos bens de consumo, incluindo um automóvel particular para cada família. As imaginações sociais de países "desenvolvidos" e também dos "menos desenvolvidos" têm poucas ideias para formas alternativas de vida que não gerem grandes emissões de carbono.

Alguns ativistas preocupados com áreas específicas da vida social pretendem identificar essas ideologias e discursos hegemônicos e o fazem de forma necessariamente parcial em relação a problemas sociais e questões políticas, porque a crítica ideológica dessa natureza requer reflexões e es- 
tudos consideráveis, mesmo para um único conjunto de questões. A teoria democrática que enfatiza a discussão como critério de legitimidade exige uma teoria mais desenvolvida sobre os tipos e mecanismos de ideologia e métodos para realizar a crítica de discussões políticas específicas. Essa crítica ideológica precisa ser capaz não apenas de analisar as interações e falas específicas mas também de teorizar sobre como a mídia contribui para naturalizar pressupostos e tornar difícil aos participantes de uma discussão falar fora de um determinado conjunto de conceitos e imagens. ${ }^{8}$ Por desconfiar de que alguns acordos mascaram relações de poder injustas, o ativista acredita que é importante continuar a questionar esses discursos e os processos deliberativos que dependem deles, e, muitas vezes, tem que fazê-lo por meios não discursivos - filmes, música, imagens poéticas e expressões de zombaria e desejo realizadas de forma turbulenta e até mesmo lúdica, voltadas não a impor o consentimento, mas a incomodar a complacência. Uma meta do ativista é nos fazer pensar sobre o que estamos fazendo, romper uma corrente de pensamento, em vez de tecer um argumento.

Apresentei a democrata deliberativa e o ativista como dois personagens distintos, com diferentes recomendações sobre as melhores formas de engajamento político. Essa oposição excludente entre as posturas é artificial, claro. Muitas pessoas e organizações se deslocam de uma posição a outra em suas vidas políticas, dependendo das questões em jogo, daqueles com quem estão interagindo ou se defrontando e do que consideram como possibilidades de ação e realização. Coloquei as posições em diálogo entre si precisamente porque acho que ambas são importantes para a teoria e a prática democráticas.

Porém, separei as posições em duas personagens opostas para destacar a postura ativista mais do que a teoria democrática recente tem feito e lançar um olhar crítico sobre algumas tendências da teoria e da prática democráticas deliberativas. As acusações do ativista são sérias e levantam algumas questões não debatidas na teoria deliberativa recente. A partir desse diálogo, tiro duas conclusões sobre os rumos da teoria democrática.

Primeiro, a teoria democrática deve manter uma distância das práticas democráticas nas atuais circunstâncias estruturais. Embora os teóricos

8 John Thompson apresenta uma teoria contemporânea da ideologia que inclui a análise dos meios de comunicação (Thompson, 1990). John Dryzek tem uma discussão útil da ideologia em Democracy in capitalist times (ver Dryzek, 1996, cap. 6). 
devam aprender com os processos de discussão e tomada de decisões em curso e, como cidadãos, participar deles de todas as maneiras que pareçam mais justas e eficazes, nós devemos resistir à tentação de considerar que os ideais da democracia deliberativa são postos em prática quando autoridades ou fundações constroem procedimentos influenciados por essas ideias. A teoria democrática, incluindo a teoria da democracia deliberativa, deve se ver principalmente como uma teoria crítica, que expõe as exclusões e restrições em processos supostamente justos de tomada real de decisões, o que torna suspeita a legitimidade de suas conclusões.

Em segundo lugar, podemos negar que a democracia deliberativa recomende que os cidadãos estejam sempre dispostos a se envolver discursivamente com todos os interesses e segmentos sociais, expressando razoavelmente opiniões e criticando os outros. Podemos conceber a troca de ideias e processos de comunicação que ocorre em uma democracia vibrante como sendo muito mais turbulenta, desordenada e descentrada, para usar a expressão de Habermas (1996, cap. 7). Nessa conceituação alternativa, processos de comunicação democrática engajada e responsável incluem manifestações de rua e ocupações, obras musicais e desenhos animados, tanto quanto os discursos parlamentares e cartas ao editor. A comunicação democrática normativamente emblemática, nesse caso, passa de uma simples disposição de dar motivos para nossas próprias reivindicações e ouvir os outros para entender de forma mais ampla a geração e a influência da opinião pública. Neste entendimento mais amplo, os participantes formulam apelos razoáveis à justiça e também expõem as origens e consequências das desigualdades estruturais na lei, os termos hegemônicos do discurso e o ambiente da prática cotidiana.

Mesmo que sigamos essas recomendações, contudo, a dissonância entre as posturas da democrata deliberativa e do ativista não se dissolve. Indivíduos e organizações que procuram combater a injustiça e promover a justiça precisam de ambos para debater com os outros e convencê-los de que há injustiças que devem ser corrigidas e a protestar e participar de ação direta. Mas, geralmente, os dois tipos de atividades não podem ocorrem em conjunto e, por esse motivo, um deles pode ofuscar o outro. As melhores teorias e práticas democráticas vão afirmar os dois, ao mesmo tempo que reconhecem a tensão entre eles. 


\section{Referências}

BOHMAN, John (1996). Public deliberation. Cambridge (MA): MIT Press. (2000). "Distorted communication: formal pragmatics as a critical theory", em HAHN, Lewis E. (ed.). Perspectives on Habermas. Indianapolis: Open Court.

COHEN, Jean \& ARATO, Andrew (1992). Civil society and political theory. Cambridge (MA): MIT Press.

DRYZEK, John (1996). Democracy in capitalist times. Oxford: Oxford University Press.

(2000). Deliberative democracy and beyound: liberals, critics, contestations. Oxford: Oxford University Press.

FISHKIN, James Fishkin (1995). The voice of the people. New Haven: Yale University Press.

GUTTMAN \& THOMPSON (1996). Democracy and disagreement. Cambridge (MA): Harvard University Press.

HABERMAS, Jürgen (1970). "On systematically distorted communication". Inquiry, n. 13, p. 205-218.

(1996) Between facts and norms. Cambridge (MA): MIT Press.

SHAPIRO, Ian (1999). "Enough of deliberation: politics is about interests and power", em MACEDO, Stephen (ed.). Deliberative politics: essays on democracy and disagreement. Oxford: Oxford University Press.

THOMPSON, John (1990) Ideology and modern culture. Stanford: Stanford University Press.

WALZER, Michael (1999). “Deliberation, and what else?”, em MACEDO, Stephen (ed.). Deliberative politics: essays on democracy and disagreement. Oxford: Oxford University Press.

YOUNG, Iris M. (1999). "Justice, inclusion and deliberative democracy", em MACEDO, Stephen (ed.). Deliberative politics: essays on democracy and disagreement. Oxford: Oxford University Press.

(2000). Inclusion and democracy. Oxford: Oxford University Press.

\section{Resumo}

Neste artigo, Iris Young discute o papel dos protestos e da ação direta na democracia. Sua estratégia para avaliar os argumentos a favor e contra a ação direta é o diálogo hipotético entre duas personagens, uma ativista e uma democrata deliberativa. Considerando como 
ambas lidam com os conflitos e desigualdades nas democracias e como definem a boa cidadania, ela discute os limites e potenciais dessas abordagens teóricas e práticas. Revelando conflitos que não podem ser ultrapassados e possíveis continuidades entre elas, a autora destaca que os protestos são tão necessários às democracias quanto o diálogo e a persuasão. Faz, assim, a crítica ao potencial paralisante da democracia deliberativa, em sua busca por consensos amplos.

Palavras-chave: ativismo, deliberacionismo, democracia, protestos, ação política direta.

\section{Abstract}

In this article, Iris Young discusses the role of protests and direct action in democracy. Her strategy to evaluate arguments for and against direct action is a hypothetical dialogue between two characters, an activist and a deliberative democrat. Considering how both deal with conflicts and inequities in democracies and how they define good citizenship, she discusses limits and potentials of those theoretical approaches and practices. Revealing conflicts that cannot be bypassed and possible continuities between them, the author underlines that protests are needed in democracies as much as dialogue and persuasion. She criticises the paralyzing potencial of deliberative democracy, as it attempts to accomplish broad consensus.

Keywords: activism, deliberative democracy, consensus, protests, direct action. 